\title{
The influences of accelerated aging on mechanical properties of veneering ceramics used for zirconia restorations
}

\author{
Huinan LUO ${ }^{1}$, Xuehua TANG ${ }^{2,4}$, Zhen DONG ${ }^{1}$, Hui TANG ${ }^{3}$, Takashi NAKAMURA ${ }^{4}$ and Hirofumi YATANI ${ }^{4}$ \\ ${ }^{1}$ Department of Stomatology, Jinling Hospital, Nanjing University School of Medicine, Nanjing, 210002, China \\ ${ }^{2}$ Department of Stomatology, The First Affiliated Hospital of Nanjing Medical University, Nanjing 210029, China \\ ${ }^{3}$ Institute of Stomatology, Nanjing Medical University, Nanjing 210029, China \\ ${ }^{4}$ Department of Fixed Prosthodontics, Osaka University Graduate School of Dentistry, Osaka 565-0871, Japan \\ Corresponding author, Xuehua TANG; E-mail: t-xuehua2008@hotmail.com
}

\begin{abstract}
This study evaluated the influences of accelerated aging on the mechanical properties of veneering ceramics used for zirconia frameworks. Five different veneering ceramics for zirconia frameworks were used. Twenty specimens were fabricated for each veneering ceramic. All specimens were divided into two groups. One was subjected to accelerated aging and the other was used as a control. Accelerated aging was performed in distilled water for $5 \mathrm{~h}$ at $200^{\circ} \mathrm{C}$ and $2 \mathrm{~atm}$. The density, open porosity, surface roughness, three-point flexural strength, and Vickers hardness were measured. The results showed that the density, open porosity, and surface roughness of all examined veneering ceramics were changed by the accelerated aging process. Accelerated aging was also found to have a positive effect on strength and a negative effect on the hardness.
\end{abstract}

Keywords: Zirconia, Veneering ceramics, Accelerated aging, Mechanical properties

\section{INTRODUCTION}

Low temperature degradation of zirconia and veneering ceramics fractures have recently attracted considerable interest for zirconia-based restorations ${ }^{1-4}$. However, studies that simulate aging of the veneering ceramics are rarely described.

Low temperature degradation occurs in zirconia through aging in water. This causes a decrease in the physical properties through spontaneous phase transformation of the zirconia crystals from the tetragonal phase to the weaker monoclinic phase ${ }^{3,4)}$. Factors that influence veneering ceramic fractures include coefficient mismatch of thermal expansion (CET) between the veneering porcelain and the zirconia substructure ${ }^{5)}$, design of the framework ${ }^{6,77}$, overloading and fatigue ${ }^{8,9)}$, the low fracture toughness of veneering ceramics $^{1,10)}$, veneering techniques ${ }^{11,12)}$, wear ${ }^{13)}$, cooling times ${ }^{14)}$, etc.

The oral environment is very harsh due to many factors including temperature changes, $\mathrm{pH}$ shifts, and mechanical loads by chewing. Therefore, the durability of veneering ceramics is especially important for maintaining mechanical properties, esthetics, and longevity of the restorations ${ }^{15-17)}$ and preventing the accumulation of plaque, the colonization and adhesion of bacteria, chipping, and the abrasion of antagonist teeth $^{13,15,18,19)}$.

In clinical practice, the materials directly exposed to the oral environment are primarily veneering ceramics for zirconia-based restorations. Water is the primary chemical component of the wet oral environment.

Color figures can be viewed in the online issue, which is available at J-STAGE.

Received Apr 10, 2015: Accepted Jul 31, 2015

doi:10.4012/dmj.2015-115 JOI JST.JSTAGE/dmj/2015-115
It dissolves glass by hydration, hydrolysis, and ionexchange reactions. The result of this dissolution gives rise to selective leaching of alkali ions in ceramic materials and changes in the surface characteristics and mechanical properties ${ }^{17,20)}$. The chemical durability of ceramic materials is influenced by a variety of factors such as the composition and microstructure of ceramic materials, the chemical character of the medium, exposure time, and temperature ${ }^{17,21,22)}$.

We recently evaluated the effects of aging on the surface textures of veneering ceramics for zirconia frameworks. The results show that the surface textures of all studied veneering ceramics were changed upon accelerated aging ${ }^{23)}$. Therefore, we think that the aging may also influence the mechanical properties of these ceramics. The purpose of this study was to evaluate the effects of accelerated aging on the flexural strength and hardness of various veneering ceramics for zirconia frameworks. The hypothesis of this study is that the accelerated aging has a negative effect on the flexural strength and hardness of veneering ceramics.

\section{MATERIALS AND METHODS}

Five types of commercial veneering ceramics in a dentin (body) color for zirconia-based systems were used in this study. Leucite was present in Vintage ZR (ZR), Cerabien ZR (CZR), and VitaVM9 (VM9) (Table 1).

\section{Specimen preparation}

Twenty specimens of each veneering ceramic were fabricated. Ceramic powder and an appropriate amount of the indicated liquid were mixed under vacuum to form a slurry. This was then poured into a rectangular 
Table 1 Veneering ceramics used in the investigation

\begin{tabular}{lcccc}
\hline Veneering ceramic & Code & Shade & Manufacturer & Composition* \\
Vintage ZR & ZR & A2 & Shofu, Kyoto, Japan & $\begin{array}{c}\text { Aluminosilicate glass, } \\
\text { leucite, etc. }\end{array}$ \\
Cerabien ZR & CZR & A2 & Noritake, Nagoya, Japan & $\begin{array}{c}\text { Potassium aluminosilicate } \\
\text { glass, leucite, etc. }\end{array}$ \\
Vita VM9 & VM9 & $2 \mathrm{M} 2$ & $\begin{array}{c}\text { Vita, Zahnfabrik, } \\
\text { Bad Säckingen, Germany }\end{array}$ & $\begin{array}{c}\text { Feldspar, alumina, cerium } \\
\text { leucite, oxide, etc. }\end{array}$ \\
Cercon ceram KISS & KISS & A2 & $\begin{array}{c}\text { DeguDent, Hanau, } \\
\text { Germany }\end{array}$ & Silicon dioxide, alumina, etc. \\
IPS e.max ceram & e.max & A2 & $\begin{array}{c}\text { Ivoclar-Vivadent, Schaan, } \\
\text { Liechtenstein }\end{array}$ & Nanofluorapatite, etc.
\end{tabular}

*Composition as given by manufacturers

Table 2 Firing schedules of the specimens

\begin{tabular}{cccccc}
\hline $\begin{array}{c}\text { Veneering } \\
\text { ceramic }\end{array}$ & $\begin{array}{c}\text { Pre-drying } \\
\text { temperature }\left({ }^{\circ} \mathrm{C}\right)\end{array}$ & $\begin{array}{c}\text { Pre-drying time } \\
(\mathrm{min})\end{array}$ & $\begin{array}{c}\text { Heating rate } \\
\left({ }^{\circ} \mathrm{C} / \mathrm{min}\right)\end{array}$ & $\begin{array}{c}\text { Firing temperature } \\
\left({ }^{\circ} \mathrm{C}\right)\end{array}$ & $\begin{array}{c}\text { Holding time } \\
(\mathrm{min})\end{array}$ \\
\hline ZR & 650 & 6 & 55 & 910 & 1 \\
CZR & 600 & 10 & 45 & 935 & 1 \\
VM9 & 500 & 6 & 55 & 510 & 830 \\
KISS & 450 & 5 & 50 & 750 & 1.5 \\
e.max & 403 & 8 & 50 & 1 \\
\hline
\end{tabular}

silicon mold with internal dimensions of $30 \times 6 \times 4 \mathrm{~mm}$. After vibration-condensation, these specimens were fired according to the manufacturers' instructions (Table 2). Firing was performed 6 times in a vacuum porcelain furnace (Twin Mat, Shofu, Kyoto, Japan). After firing, the specimens were processed using 100-, 400-, and 800-diamond discs, and they were polished to final dimensions of $4.0 \pm 0.2 \mathrm{~mm}$ in width, $1.2 \pm 0.2 \mathrm{~mm}$ in thickness and at least $20 \mathrm{~mm}$ in length using media containing $15 \mu \mathrm{m}$ to $20 \mu \mathrm{m}$ diamond grit following the guidelines of ISO 6872: 2008 (three-point flexural strength ${ }^{24)}$. Twenty specimens were randomly divided into two groups for each type of veneering ceramic. The accelerated aging test was performed on ten specimens (the aged specimens), and the other ten specimens served as controls (unaged specimens).

\section{Accelerated aging test}

An accelerated aging test was performed with an electric drying oven (DRA330DA, Advantec, Tokyo, Japan) and a decomposition container consisting of an inner Teflon vessel and an outer stainless steel vessel. Specimens were washed 3 times with ethyl alcohol, dried, and sealed in the Teflon vessel. Inside this vessel, the specimens were supported by a Teflon support screen and immersed in distilled water. The specimens were treated at 2 atm and $200^{\circ} \mathrm{C}$ for $5 \mathrm{~h}$. To reduce the risk of micro-crack formation, the temperature of the electric drying oven was slowly increased until the storage temperature of $200^{\circ} \mathrm{C}$. Guideline ISO 13356: 2008 is referenced in this study ${ }^{25)}$.

\section{Density and open porosity}

The density and open porosity of all the unaged and aged specimens were determined by Archimedes' method ${ }^{11}$. The following equations were used:

$$
\begin{aligned}
& \rho=\rho_{\mathrm{w}} \times \mathrm{W}_{1} /\left(\mathrm{W}_{3}-\mathrm{W}_{2}\right) \\
& \mathrm{P}=\left(\mathrm{W}_{3}-\mathrm{W}_{1}\right) /\left(\mathrm{W}_{3}-\mathrm{W}_{2}\right) \times 100 \%
\end{aligned}
$$

( $\rho$ : density; P: open porosity; $\rho_{\mathrm{w}}=0.998203 \mathrm{~g} / \mathrm{cm}^{3}$ at $20^{\circ} \mathrm{C}$, namely, the density of water at the testing temperature; $\mathrm{W}_{1}$ : dry weight; $\mathrm{W}_{2}$ : submerged weight; $\mathrm{W}_{3}$ : wet weight).

\section{Surface roughness}

After the accelerated aging test, the specimens were removed from the Teflon jars, cleaned ultrasonically in distilled water for $10 \mathrm{~min}$, and dried in the air. The average roughness ( $\mathrm{Ra}$ ) for the unaged and aged specimens was evaluated by laser profilometry using a confocal laser scanner profilometer (LEXT OLS4000, Olympus, Tokyo, Japan). The diameter of the laser beam was $0.2 \mu \mathrm{m}$. Four separate areas were measured on each specimen, and 10 specimens were observed for each type 
of ceramic and set of conditions. The measured area was $256 \times 256 \mu \mathrm{m}$ and the distance between separate scans was more than $3 \mu \mathrm{m}$. The resolution used in the $\mathrm{X}, \mathrm{Y}$, and $\mathrm{Z}$ directions were $0.02 \mu \mathrm{m}, 0.02 \mu \mathrm{m}$, and $0.01 \mu \mathrm{m}$, respectively.

\section{Flexural strength}

After the evaluation of surface roughness, flexural strength was measured with the three-point bending test. The 10 specimens of the aged and unaged specimens were tested using a universal testing machine (Autograph AG-5000B, Shimadzu, Kyoto, Japan) resting on a self-aligning fixture with a span of $14 \mathrm{~mm}$. Bending tests were conducted at a crosshead speed of $0.5 \mathrm{~mm} /$ min in accordance with ISO 6872 guidelines.

\section{Hardness}

One fractured segment of each specimen was chosen randomly for the hardness test after the three-point bending test ( $n=10$ for each group). Hardness was measured using a Vickers micro-hardness tester (HM102, Mitutoyo, Kawasaki, Japan) with a load of $9.8 \mathrm{~N}$ and a dwell time of $20 \mathrm{~s}$.

\section{Scanning electron microscopy (SEM)}

To determine the effects of accelerated aging on surface topography, a specimen was taken randomly from the control and aged specimens, cleaned ultrasonically in distilled water for $10 \mathrm{~min}$, and dried in the air for SEM (JSM-6390LA, JEOL, Tokyo, Japan).

\section{Statistical analysis}

A $t$-test assessed the differences in surface roughness, flexural strength, and Vickers hardness between the unaged and aged specimens. A significance level of 5\% was preset (SPSS 17.0, SPSS, Chicago, IL, USA).

\section{RESULTS}

Density and open porosity

For all veneering ceramics, the aged specimens were less dense than the non-aged specimens and had more open porosity than the unaged specimens (Table 3).
Significant differences were observed in density between all unaged and aged specimens except e.max $(p<0.05)$.

\section{Surface roughness}

The Ra values of all unaged specimens were $0.145-0.157$ $\mu \mathrm{m}$, and those of the aged specimens were $0.176-0.257$ $\mu \mathrm{m}$ (Fig. 1). The Ra values of all aged specimens were greater than those of the unaged specimens with the exception of e.max $(p=0.000)$. The $\mathrm{Ra}$ value of aged specimen was lower than that of the unaged e.max specimen $(p=0.035)$.

\section{Flexural strength}

The flexural strengths of all the aged specimens with the exception of KISS were significantly higher than those of the unaged specimens ( $p<0.01$; Fig.2). No significant difference was found for the KISS specimens $(p=0.791)$.

\section{Hardness}

The Vickers hardness of all veneering ceramics ranged from 6.07-7.58 GPa for the unaged specimens, and from 4.81-5.01 GPa for the aged specimens. The Vickers hardness of all the aged specimens were significantly lower than those of the unaged specimens $(p=0.000$; Fig. 3).

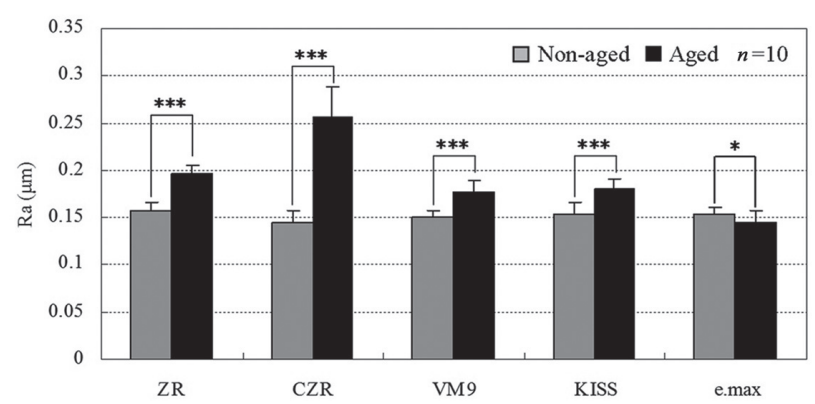

Fig. 1 Surface roughness of aged and unaged specimens $\left({ }^{*}: p<0.05 ;{ }^{* *}: p<0.01 ;{ }^{* * *}: p<0.001\right)$.

Table 3 Density $\left(\mathrm{g} \cdot \mathrm{cm}^{-3}\right)$ and Open porosity [\%] of veneering ceramics for the non-aged and aged specimens $(n=10)$

\begin{tabular}{|c|c|c|c|c|}
\hline \multirow{2}{*}{ Veneering ceramic } & \multicolumn{2}{|c|}{ Density $\left(\mathrm{g} \cdot \mathrm{cm}^{-3}\right)$} & \multicolumn{2}{|c|}{ Open porosity [\%] } \\
\hline & Non-aged & Aged & Non-aged & Aged \\
\hline $\mathrm{ZR}$ & $2.3839(0.0732)$ & $2.0973(0.0842)^{* * *}$ & $2.15(1.92)$ & $2.47(1.13)$ \\
\hline $\mathrm{CZR}$ & $2.3324(0.0701)$ & $2.1681(0.0422)^{*}$ & $2.01(1.53)$ & $3.12(1.40)$ \\
\hline VM9 & $2.37902(0.0483)$ & $2.2873(0.0702)^{*}$ & $2.40(1.93)$ & $3.23(2.21)$ \\
\hline KISS & $2.4995(0.0828)$ & $2.3957(0.0561)^{*}$ & $1.71(0.79)$ & $1.79(1.22)$ \\
\hline e.max & $2.3847(0.0842)$ & $2.2556(0.1946)$ & $2.13(0.88)$ & $2.73(1.15)$ \\
\hline
\end{tabular}

( ): standard deviation;

$*$, ** Significant differences $(*: p<0.05 ; * *: p<0.001)$ between the non-aged and aged specimens. 


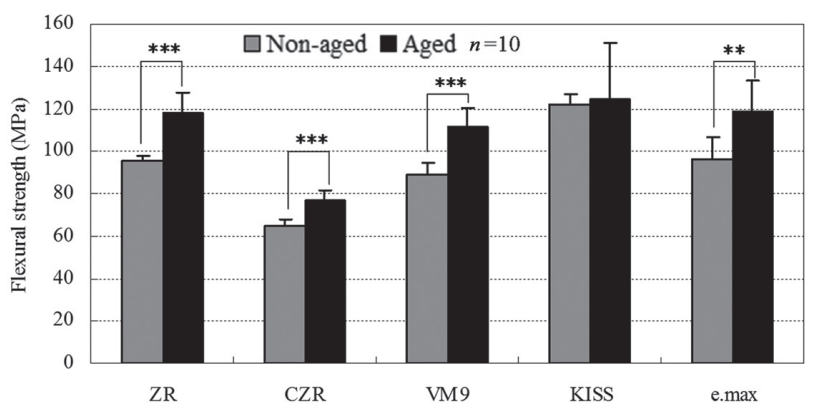

Fig. 2 Flexural strength of aged and unaged specimens $(* *: p<0.01 ; * * *: p<0.001)$.

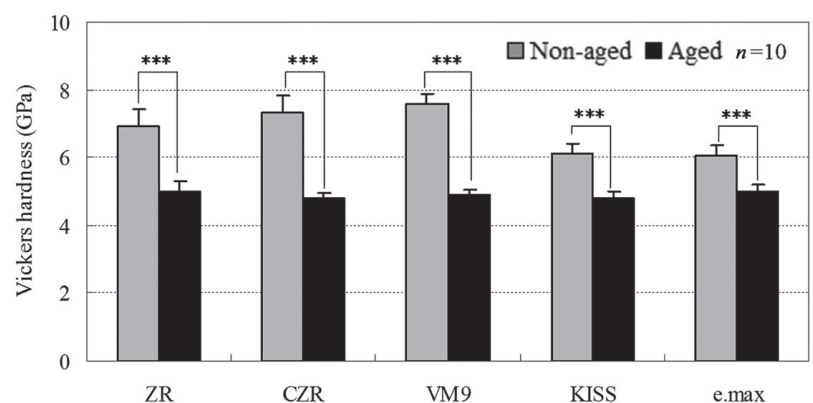

Fig. 3 Vickers hardness of aged and unaged specimens $(* *: p<0.01 ; * * *: p<0.001)$.
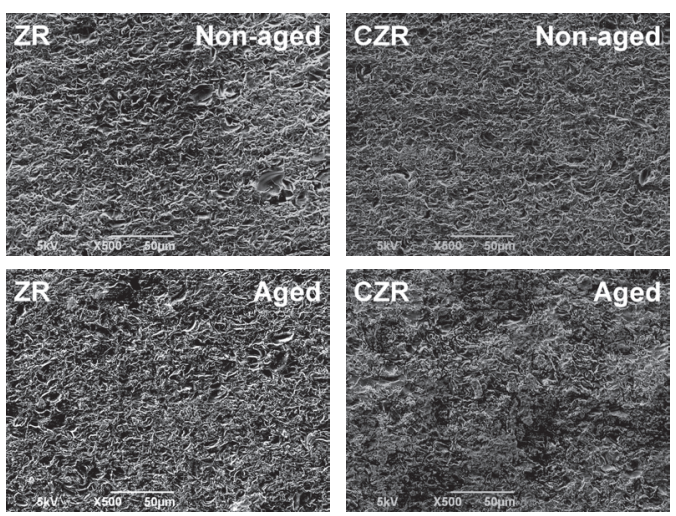
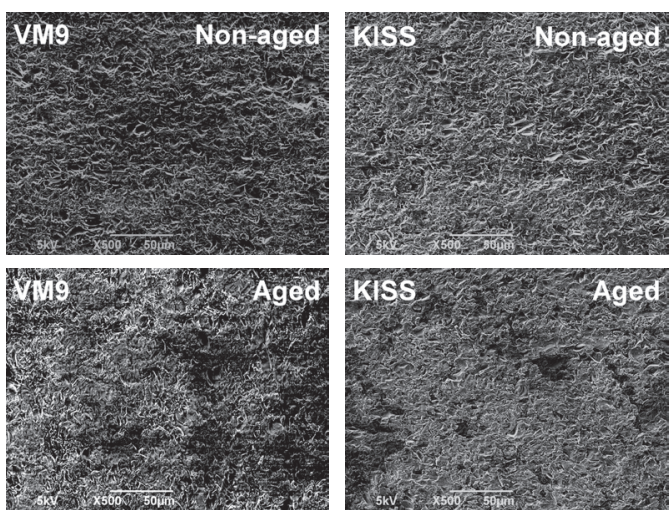

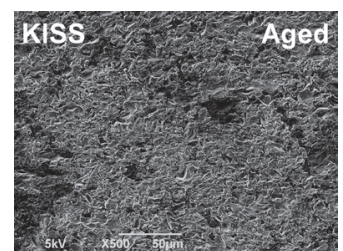

Fig. 4 SEM images of aged and unaged specimens.

\section{SEM analysis}

All unaged specimens had dense surfaces with a number of small porosities. The surfaces of all aged specimens showed significant differences from those of all unaged specimens, specifically aggressive destruction. The surfaces of all aged specimens presented numerous pores and irregular cracks for ZR, CZR, VM9, and KISS. The surface of the aged specimens seem to display numerous deposits of particles for e.max. SEM images of the surface topography for the aged and unaged specimens are shown in Fig. 4.

\section{DISCUSSION}

Metal-ceramic systems are established dental materials. Zirconia-based restorations are the most recent introduction to the dental field and are broadly deployed. Although numerous veneering ceramics matching the zirconia framework have appeared in the dental market, a study concerning the aging of these veneering ceramics is absent in the literature. Therefore, this study was carried to understand the effects of aging on the mechanical properties of veneering ceramics for zirconia frameworks.

There have been many studies on the aging of zirconia. However, experimental guidelines for the aging of veneering ceramics have not yet been established.
Consequently, the latest version of an ISO standard (ISO 13356: 2008) for implants and surgery using ceramic materials based on Y-TZP is referenced in this study ${ }^{25)}$. According to that standard, the conditions of accelerated aging were $5 \mathrm{~h}$ at $134^{\circ} \mathrm{C}$ and $2 \mathrm{~atm}$ in an autoclave. This simulates between 5 and 20 years of exposure at body temperature ${ }^{26-28)}$. Another treatment, at $200^{\circ} \mathrm{C}$ was also used because it had been reported in a prior study ${ }^{29)}$. This is greater than the temperature within the oral cavity in consideration of the complexity and rigor of the oral environment and the use of a water bath in this study. It was also used to increase the sensitivity of the experimental results. An earlier investigation showed that the effect of changing the temperature was essentially the same as that of changing the duration of exposure, and temperature did not substantially affect the mechanism of degradation of the glass surfaces, only the kinetics ${ }^{21}$. In this way, examining aging from low temperatures to high temperatures may have the same effect as examining aging of the same specimen over time.

The results of this study showed that the open porosity of all the specimens became higher after accelerated aging. This may be because of the selective leaching of the alkali ions by ion-exchange reactions ${ }^{20,30,31)}$. K and $\mathrm{Na}$ were generally added as glass network modifiers, and the leaching of these modifiers 

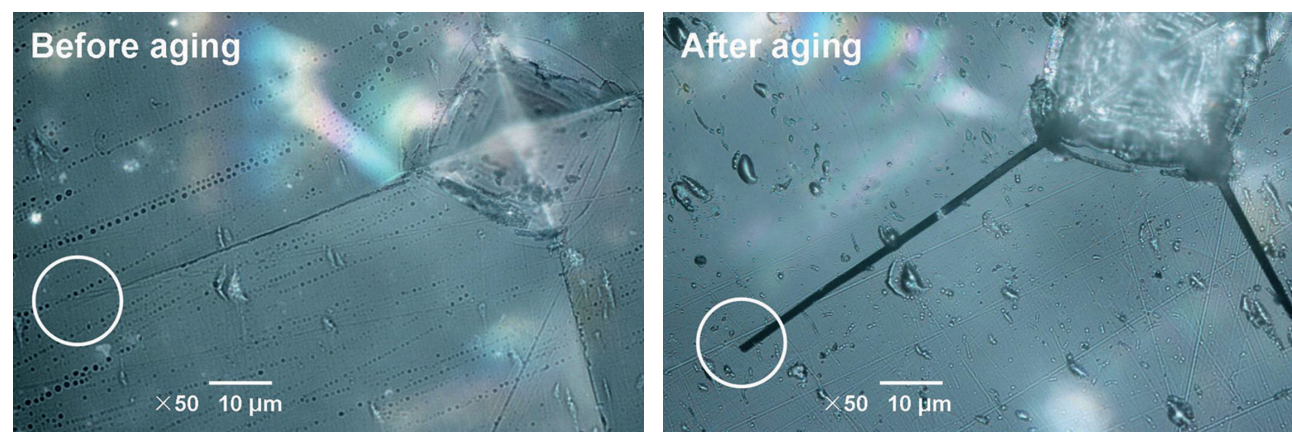

Fig. 5 Crack images before and after accelerated aging (circle: crack tip) (ZR).

may create pores or channels within the glassy matrix. However, the dissociation reaction of $\mathrm{H}_{2} \mathrm{O}$ may also have occurred under these experimental conditions. Hydrogen ions and hydroxide ions are strongly corrosive. Hydrogen ions are small and reactive and can penetrate the surface layer of the ceramics, creating pores ${ }^{20,31}$. In addition, another investigation has shown there to be many leucite crystals and microcracks in ZR, CZR, and VM9, and the largest cristobalite crystals were also found for $\mathrm{CZR}^{1)}$. The closed porosity and microcracks within the specimens may be opened by aging of the surface.

The $\mathrm{Ra}$ values of all the aged specimens with the exception of e.max showed a significant increase versus the unaged specimens, and that of e.max showed a significant decrease. These are consistent with previous findings on acid corrosion ${ }^{22,32,33)}$. They are supported by the results of the current SEM observations, which showed small porosities on the surfaces of all unaged specimens. Nevertheless, a number of pores and irregular cracks were prominent on the surfaces of all aged specimens for ZR, CZR, VM9, and KISS ${ }^{23)}$, and numerous particle deposits were present on the surfaces of the aged e.max specimen. These results are consistent with those of the density and open porosity evaluations conducted here. In clinical practice, the increase in surface roughness for dental materials exposed to the oral environment has many possible negative effects including plaque retention, the colonization, or adhesion of bacteria, and the abrasiveness of the opposing surfaces ${ }^{13,15,18,19)}$. In addition, some investigations also revealed that a rougher surface makes it easier to concentrate an applied stress, which gives rise to chipping. This makes it undesirable in clinical practice.

In the present study, the flexural strength of all aged specimens was greater than that of the unaged specimens. We first thought that the incisive tip of the ceramic block was blunted by the dissolution and subsequent precipitation of silica glass during the accelerated aging process ${ }^{34}$. In order to prove this, a crack was generated on a polished surface using the Vickers micro-hardness tester (HM-102) using a load of $9.8 \mathrm{~N}$ and a dwell time of $20 \mathrm{~s}$. The crack shape before and after the accelerated aging was observed by optical microscopy (LV-100POL, Nikon, Tokyo, Japan). As a result, the incisive tip of the crack became more blunt after accelerated aging (Fig. 5).

Other sources of increased strength include chemical tempering through ion exchange or a change in material properties to produce a ductile surface layer. This change would presumably be caused by hydroxyl ion diffusion into the surface ${ }^{35}$. In a previous study, the crystalline phase peaks changed after accelerated aging ${ }^{23)}$. This is possibly related to the changes in flexural strength as well, but requires future study to further elucidate. Higher strength in veneering ceramics has always been desired by clinicians and researchers. Strengthening approaches include optimization of the leucite grain in glass ceramics or a change in fabrication mode ${ }^{10,36)}$. Therefore, we rejected the hypothesis that accelerated aging decreases flexural strength.

All aged specimens had a significantly lower Vickers hardness than the unaged specimens. This result is in accordance with an earlier degrading experiment using naturally acidic agents ${ }^{17}$. This may be because of the porosity or roughness of the surface. A number of investigations have revealed that the porosity or roughness of the surface is greater and the hardness is less pronounced ${ }^{37-39)}$. The results of this study showed that the open porosity of all aged specimens to be greater than that of the unaged specimens and the surfaces of all aged specimens were rougher than those of all unaged specimens except those treated with e.max.

Hardness is a particularly important feature of dental material that affects the occlusal wear resistance of the material. The hardness of a ceramic is directly proportional to the abrasiveness of the opposing surfacehardness alone cannot explain abrasive wear. In fact there is no correlation between hardness and wear, and wear appears to be more related to roughness and fracture resistance than to strict hardness values ${ }^{40)}$. Clinically, the wear caused by aging, chewing and clenching as well as the porosity of the restorations may roughen the ceramic surface. A bulge that develops on a rough surface may become an occlusal loading point. As a result, these bulges have the potential to develop cracks. Therefore the likelihood of fracture increase ${ }^{13)}$. The results of this study of hardness are probably undesirable information for endeavors that increase 
resistance to fatigue and prevent premature material failure. It is here accepted that accelerated aging has a negative effect on hardness of veneering ceramics.

The composition and microstructure of newly launched veneering ceramics may differ from those of traditional veneering ceramics, which could affect the chemical durability and mechanical properties. The reliability of these veneering ceramics cannot be extrapolated from measurements of one ceramic formulation to another composition or conditions. In addition, it is also possible that aging in this experiment is different from aging in the mouth, in which crystals other than zirconia may be included in the veneering ceramics. Therefore, further studies are required to elucidate the reliability of these veneering ceramics and aging.

\section{CONCLUSION}

In this study, we studied the effects of accelerated aging on the mechanical properties of veneering ceramics used for zirconia frameworks. Accelerated aging had a positive effect on the flexural strength and a negative effect on the hardness.

\section{ACKNOWLEDGMENTS}

This study was supported in part by a Grant-in-Aid for Scientific Research (No. 205922620) from the Japanese Ministry of Education, Culture, Sports, Science, and Technology, for which we express our thanks. The authors also would like to thank Mr. YOSHIMOTO, Mr. TAKAHASHI, and Mr. WATANABE of Shofu and Mr. ISHIDA of the Dental Studio Laboratory for their technical assistance with this study.

\section{REFERENCES}

1) Tang $X$, Nakamura T, Usami H, Wakabayashi K, Yatani H. Effects of multiple firings on the mechanical properties and microstructure of veneering ceramics for zirconia frameworks. J Dent 2012; 40: 372-380.

2) Wang G, Zhang S, Bian C, Kong H. Fracture mechanics analyses of ceramic/veneer interface under mixed-mode loading. J Mech Behav Biomed Mater 2014; 39: 119-128.

3) Keuper M, Berthold C, Nickel KG. Long-time aging in 3 mol.\% yttria-stabilized tetragonal zirconia polycrystals at human body temperature. Acta Biomater 2014; 10: 951-959.

4) Hübsch C, Dellinger P, Maier HJ, Stemme F, Bruns M, Stiesch M, Borchers L. Protection of yttria-stabilized zirconia for dental applications by oxidic PVD coating. Acta Biomater 2015; 11: 488-493.

5) Dittmer MP, Borchers L, Stiesch M, Kohorst P. Stresses and distortions within zirconia-fixed dental prostheses due to the veneering process. Acta Biomater 2009; 5: 3231-3239.

6) Silva NR, Bonfante EA, Rafferty BT, Zavanelli RA, Rekow ED, Thompson VP, Coelho PG. Modified Y-TZP core design improves all-ceramic crown reliability. J Dent Res 2011; 90: 104-108.

7) Kirsten A, Parkot D, Raith S, Fischer H. A cusp supporting framework design can decrease critical stresses in veneered molar crowns. Dent Mater 2014; 30: 321-326.

8) Bulpakdi P, Taskonak B, Yan J, Mecholsky JJ Jr. Failure analysis of clinically failed all-ceramic fixed partial dentures using fractal geometry. Dent Mater 2009; 25: 634-640.

9) Lorenzoni FC, Martins LM, Silva NR, Coelho PG, Guess PC, Bonfante EA, Thompson VP, Bonfante G. Fatigue life and failure modes of crowns systems with a modified framework design. J Dent 2010; 38: 626-634.

10) Beuer F, Schweiger J, Eichberger M, Kappert HF, Gernet W, Edelhoff D. High-strength CAD/CAM-fabricated veneering material sintered to zirconia copings-a new fabrication mode for all-ceramic restorations. Dent Mater 2009; 25: 121-128.

11) Baldassarri M, Zhang Y, Thompson VP, Rekow ED, Stappert CF. Reliability and failure modes of implant-supported zirconium-oxide fixed dental prostheses related to veneering techniques. J Dent 2011; 39: 489-498.

12) Guess PC, Bonfante EA, Silva NR, Coelho PG, Thompson VP. Effect of core design and veneering technique on damage and reliability of Y-TZP-supported crowns. Dent Mater 2013; 29: 307-316.

13) Preis V, Behr M, Kolbeck C. Hahnel S, Handel G, Rosentritt $\mathrm{M}$. Wear performance of substructure ceramics and veneering porcelains. Dent Mater 2011; 27: 796-804.

14) Göstemeyer G, Jendras M, Dittmer MP, Bach FW, Stiesch M, Kohorst P. Influence of cooling rate on zirconia/veneer interfacial adhesion. Acta Biomater 2010; 6: 4532-4538.

15) Milleding P, Carlén A, Wennerberg A, Karlsson S. Protein characterization of salivary and plasma biofilms formed in vitro on non-corroded and corroded dental ceramic materials. Biomaterials 2001; 22: 2545-2555.

16) Raptis NV, Michalakis KX, Hirayama H. Optical behavior of current ceramic systems. Int J Periodontics Restorative Dent 2006; 26: 31-41.

17) Kukiattrakoon B, Hengtrakool C, Kedjarune-Leggat U. Degradability of fluorapatite-leucite ceramics in naturally acidic adents. Dent Mater J 2010; 29: 502-501.

18) Hahnel S, Rosentritt M, Handel G, Bürgers R. Surface characterization of dental ceramics and initial streptococcal adhesion in vitro. Dent Mater 2009; 25: 969-975.

19) Saadaldin SA, Rizkalla AS. Synthesis and characterization of wollastonite glass-ceramics for dental implant applications. Dent Mater 2014; 30: 364-371.

20) Bunker BC. Molecular mechanisms for corrosion of silica and silicate glasses. J Non-Cryst Solids 1994; 179: 300-308.

21) Lynch ME, Folz DC, Clark DE. Use of FTIR reflectance spectroscopy to monitor corrosion mechanisms on glass surface. J Non-Cryst Solids 2007; 353: 2667-2674.

22) Ccahuana VZ, Ozcan M, Mesquita AM, Nishioka RS, Kimpara ET, Bottino MA. Surface degradation of glass ceramics after exposure to acidulated phosphate fluoride. J Appl Oral Sci 2010; 18: 155-165.

23) Tang $X$, Tan Z, Nakamura T, Yatani H. Effects of aging on surface textures of veneering ceramics for zirconia frameworks. J Dent 2012; 40: 913-920.

24) International Standard Organization No.6872. DentistryCeramic materials. International Organization for Standardization; 2008.

25) International Standard Organization No.13356. Implants for surgery-Ceramic materials based on yttria-stabilized tetragonal zirconia (Y-TZP), 2008.

26) Ban S, Sato H, Suehiro Y, Nakanishi H, Nawa M. Biaxial flexure strength and low temperature degradation of Ce-TZP/ Al2O3 nanocomposite and Y-TZP as dental restoratives. J Biomed Mater Res B Appl Biomater 2008; 87: 492-498.

27) Kim JW, Covel NS, Guess PC, Rekow ED, Zhang Y. Concerns of hydrothermal degradation in CAD/CAM zirconia. J Dent Res 2010; 89: 91-95.

28) Flinn BD, Raigrodski AJ, Singh A, Mancl LA. Effect of hydrothermal degradation on three types of zirconias for dental application. J Prosthet Dent 2014; 112: 1377-1384.

29) Nakamura T, Usami H, Ohnishi H, Takeuchi M, Nishida H, 
Sekino T, Yatani H. The effect of adding silica to zirconia to counteract zirconia's tendency to degrade at low temperatures. Dent Mater J 2011; 30: 330-335.

30) Cesar PF, Gonzaga CC, Miranda WG Jr, Yoshimura HN. Effect of ion exchange on hardness and fracture toughness of dental porcelains. J Biomed Mater Res B Appl Biomater 2007; 83: 538-545.

31) Geisler T, Janssen A, Scheiter D, Stephan T, Berndt J, Putnis A. Aqueous corrosion of borosilicate glass under acidic conditions: A new corrosion mechanism. J Non-Cryst Solids 2010; 356: 1458-1465.

32) Milleding P, Wennerberg A, Alaeddin S, Karlsson S, Simon E. Surface corrosion of dental ceramics in vitro. Biomaterials 1999; 20: 733-746.

33) Ohara N, Koizumi H, Matsumoto Y, Nakayama D, Ogino $\mathrm{T}$, Matsumura H. Surface roughness and gloss of indirect composites etched with acidulated phosphate fluoride solution. Acta Odontol Scand 2009; 67: 313-320.

34) Ito S, Tomozawa M. Crack blunting of high-silica glass. J Am Ceram Soc 1982; 65: 368-371.
35) Griggs JA, Kishen A, Le KN. Mcchanism of strength increase for a hydrothermal porcelain. Dent Mater 2003; 19: 625-631.

36) Chen X, Chadwick TC, Wilson RM, Hill R, Cattell MJ. Crystallization of high-strength fine-sized leucite glassceramics. J Dent Res 2010; 89: 1510-1516.

37) Margha FH, Mohamed Abdel-Hameed SA, El-Shafy Ghonim NA, Ali SA, Kato S, Satokawa S, Kojima T. Crystallization behaviour and hardness of glass ceramics rich in nanocrystals of $\mathrm{ZrO}_{2}$. Ceram Int 2009; 35: 1133-1137.

38) Chavan NM, Ramakrishna M, Phani PS, Rao DS, Sundararajan G. The influence of process parameters and heat treatment on the properties of cold sprayed silver coating. Surf Coat Technol 2011; 205: 4798-4807.

39) Yeh S, Wang H, Liao H, Su S, Chang C, Kao H, Lee B. The roughness, microhardness, and surface analysis of nanocomposites after application of topical fluoride gels. Dent Mater 2011; 27: 187-196.

40) Oh WS, Delong R, Anusavice KJ. Factors affecting enamal and ceramic wear: a literature review. J Prosthet Dent 2002; 87: 451-459. 